\title{
LncRNA PRINS is involved in the development of nephropathy in patients with diabetes via interaction with Smad7
}

\author{
HAIYAN JIAO $^{1}$, DAOLIN XIE ${ }^{2}$ and YANHONG QIAO ${ }^{1}$ \\ Departments of ${ }^{1}$ Nephrology and ${ }^{2}$ Ultrasound Diagnosis, Peace Hospital of Changzhi Medical College, \\ Changzhi, Shanxi 046000, P.R. China
}

Received July 13, 2018; Accepted December 21, 2018

DOI: $10.3892 /$ etm.2019.7307

\begin{abstract}
Long non-coding RNA psoriasis-susceptibilityrelated RNA gene induced by stress (PRINS) is known to be involved in kidney ischemia reperfusion injury. The aim of the current study was to investigate the potential role of PRINS in diabetic nephropathy. The relative mRNA expression level of PRINS and SMAD family member 7 (Smad7) was examined in patients with diabetes, including patients without obvious complications $(n=43)$, patients with diabetic nephropathy $(\mathrm{n}=33)$, diabetic retinopathy $(\mathrm{n}=37)$, diabetic cardiomyopathy $(n=29)$, diabetic lung disease $(n=38)$ and healthy controls $(\mathrm{n}=48)$. Correlation analysis between the expression level of PRINS and Smad7 was analyzed by Pearson's correlation analysis. In addition, overexpression of PRINS was confirmed in mouse podocyte cells and cell viability and Smad7 protein expression was detected by MTT assay and western blot analysis, respectively. The expression levels of PRINS and Smad7 were significantly increased in patients with diabetes compared with healthy controls. In addition, the expression levels of PRINS and Smad7 were significantly increased in patients with diabetic nephropathy compared with other diabetic complications. The expression level of PRINS in mouse podocyte cells was upregulated following treatment with high glucose. A significant positive correlation between the expression level of PRINS and Smad7 was observed in patients with diabetic nephropathy. However, there was no correlation was observed in other patient groups compared with healthy controls. Overexpression of PRINS decreased the viability of mouse podocyte cells and enhanced Smad7 protein expression. Taken together, these results suggest that PRINS may be involved in the development of nephropathy in patients with diabetes.
\end{abstract}

Correspondence to: Professor Yanhong Qiao, Department of Nephrology, Peace Hospital of Changzhi Medical College, 110 Yan'an South Road, Changzhi, Shanxi 046000, P.R. China E-mail: qkwhbx9@163.com

Key words: diabetic nephropathy, long non-coding RNA psoriasis-susceptibility-related RNA gene induced by stress, SMAD family member 7

\section{Introduction}

Changes in lifestyle, particularly in developing countries has caused an increase in the incidence of diabetes and it is expected to increase significantly in the future (1). Diabetes is often accompanied by the development of complications that affect most major organ systems (2). The most common diabetes-related complications include blindness, renal failure and cardiovascular disease (2). However, one of the more serious complications associated with diabetes, diabetic nephropathy, can cause long-term kidney disease and end-stage renal disease and is a leading cause of death among patients with diabetes (3). Although there have been significant improvements in the treatment and prevention of renal damage in patients with diabetes, patient outcomes remain poor (4). Current treatment is focused on the prevention of disease progression (5). Therefore, identifying novel therapeutic targets may improve the survival of patients with diabetic nephropathy.

Smad7, which is associated with apoptosis in kidney (6), is considered to be a therapeutic target for the treatment of diabetic nephropathy (7). Several studies have demonstrated that under certain pathological conditions Smad7 can interact with several long non-coding RNAs (lncRNAs), a subgroup of non-coding RNAs whose aberrant expression is closely related to human diseases, to exert its biological functions (8-10). LncRNA psoriasis-susceptibility-related RNA gene induced by stress (PRINS) is associated with several different types of human disease, including kidney ischemia reperfusion injury and psoriasis $(11,12)$. In the current study, PRINS may be involved in the development of nephropathy in patients with diabetes via interactions with Smad7.

\section{Materials and methods}

Patients. Blood samples were collected from patients with diabetes, including patients without obvious complications $(n=43)$, patients with diabetic nephropathy $(\mathrm{n}=33)$, diabetic retinopathy $(\mathrm{n}=37)$, diabetic cardiomyopathy $(\mathrm{n}=29)$ and diabetic lung disease $(n=38)$ who were diagnosed and treated at the Peace Hospital of Changzhi Medical College (Changzhi, China) from January 2015 to January 2018. All patients were diagnosed according to the standard established by the Chinese Medical Association (2014) (13). All patients were diagnosed and treated for the first time. Patients with other more severe diseases were excluded. In 
addition, blood samples from 48 healthy control patients were also included as a control group. No significant differences in age and sex were found between the groups (Table I).

The current study was approved by the Ethics Committee at the Peace Hospital of Changzhi Medical College (Changzhi, China), and all the participants provided written informed consent.

Blood sample collection, RNA extraction and reverse transcription-quantitative polymerase chain reaction $(R T-q P C R)$. Blood samples $(20 \mathrm{ml})$ were collected from each participant $24 \mathrm{~h}$ after admission. Total RNA was extracted using TRIzol ${ }^{\circledast}$ reagent (Invitrogen; Thermo Fisher Scientific, Inc., Waltham, MA, USA), according to the manufacturer's protocol. Total RNA concentration was measured using a NanoDrop ${ }^{\mathrm{TM}} 2000$ Spectrophotometer (Thermo Fisher Scientific, Inc.) and RNA samples with a A260/A280 ratio of 1.8-2.0 were reverse transcribed into cDNA using SuperScript IV Reverse Transcriptase (Thermo Fisher Scientific, Inc.) through the following thermocycling conditions: $25^{\circ} \mathrm{C}$ for $5 \mathrm{~min} ; 50^{\circ} \mathrm{C}$ for $20 \mathrm{~min}$ and $80^{\circ} \mathrm{C}$ for $20 \mathrm{~min}$. qPCR reaction systems were prepared using $\mathrm{SYBR}^{\circledR}$ Green master mix (Bio-Rad Laboratories, Inc., Hercules, CA, USA). The following primer pairs were used for the qPCR: IncRNA PRINS forward, 5'-TCCACATCCGGATTTACCTAAAC-3' and reverse, 5'-CTGACGCACCCCTGACAGTCAG-3'; Smad7 forward, 5'-AAGTGTTCAGGTGGCCGGATCTCAG-3' and reverse, 5'-ACAGCATCTGGACAGCCTGCAGTTG-3'; and $\beta$-actin forward, 5'-GACCTCTATGCCAACACAGT-3' and reverse, 5'-AGTACTTGCGCTCAGGAGGA-3'. The thermocycling conditions used for the qPCR were: Initial denaturation at $95^{\circ} \mathrm{C}$ for $52 \mathrm{sec} ; 40$ cycles of $95^{\circ} \mathrm{C}$ for $18 \mathrm{sec}$ and $57.5^{\circ} \mathrm{C}$ for $40 \mathrm{sec}$. IncRNA PRINS and Smad7 mRNA expression levels were quantified using the $2^{-\Delta \Delta C q}$ method (14) and normalized to the internal control $\beta$-actin.

Cell culture and transfection. Mouse podocyte cells were purchased from PrimCells, LLC. (San Diego, CA, USA) and cultured with Roswell Park Memorial Institute 1640 medium (Thermo Fisher Scientific, lnc.) supplemented with $100 \mu \mathrm{g} / \mathrm{ml}$ streptomycin, $100 \mathrm{U} / \mathrm{ml}$ penicillin and $10 \%$ fetal calf serum (Sigma-Aldrich; Merck KGaA, Darmstadt, Germany) at $37^{\circ} \mathrm{C}$ in a $5 \% \mathrm{CO}_{2}$ incubator. The PRINS cDNA fragment was obtained by PCR amplification and cloned into the pEGFPC3 vector (Clontech Laboratories, Inc., Mountainview, CA, USA) to generate a PRINS expression vector. Cells at a cell density of $4 \times 10^{3} / \mathrm{ml}$ were cultured in a six-well plate overnight before transfection. Lipofectamine ${ }^{\circledR} 2000$ reagent (Thermo Fisher Scientific., Inc.) was initially mixed with expression vectors $(10 \mathrm{nM})$ to form transfection reagent-vector complexes, prior to transfection. Cells were transfected with transfection reagent-vector complexes at $37^{\circ} \mathrm{C}$ for $6 \mathrm{~h}$. PRINS overexpression was confirmed by RT-qPCR prior to subsequent experimentation. Cells were harvested at $24 \mathrm{~h}$ after transfection for subsequent experiments. In cases of D-glucose treatment, mouse podocyte cells were treated with $5 \mathrm{mM}$ (control), 10, 20 and $30 \mathrm{mM}$ D-glucose (Sigma-Aldrich; Merck $\mathrm{KGaA}$ ) for 6,12 and $18 \mathrm{~h}$, respectively, before use.

MTT assay. Cell viability was analyzed using the MTT assay. Briefly, mouse podocoyte cells were collected and single-cell
Table I. Participant information.

\begin{tabular}{lcccc}
\hline & \multicolumn{2}{c}{ Sex } & & \\
\cline { 2 - 3 } Group & $\begin{array}{c}\text { Male } \\
(\mathrm{n})\end{array}$ & $\begin{array}{c}\text { Female } \\
(\mathrm{n})\end{array}$ & $\begin{array}{c}\text { Age range } \\
\text { (years) }\end{array}$ & $\begin{array}{c}\text { Mean age } \\
\text { (years) }\end{array}$ \\
\hline C & 27 & 21 & $33-67$ & $48.1 \pm 6.2$ \\
D & 24 & 19 & $29-69$ & $48.4 \pm 7.1$ \\
DN & 18 & 15 & $30-69$ & $47.5 \pm 5.8$ \\
DR & 19 & 18 & $35-69$ & $49.4 \pm 6.6$ \\
DC & 14 & 15 & $31-70$ & $48.8 \pm 7.4$ \\
DL & 20 & 18 & $31-66$ & $47.9 \pm 6.7$ \\
\hline
\end{tabular}

C, healthy controls; D, patients with diabetes without complications; $\mathrm{DN}$, patients with diabetic nephropathy; DR, patients with diabetic retinopathy; DC, patients with diabetic cardiomyopathy; DL, patients with diabetic lung diseases.

suspensions at a density of $4 \times 10^{4}$ cells $/ \mathrm{ml}$ were prepared using Roswell Park Memorial Institute 1640 medium. Subsequently, cells were seeded into 96 -well plates at a density of $4 \times 10^{3}$ cells/well and $30 \mathrm{mM} \mathrm{D-glucose}$ was added to each well and cells were cultured for $6 \mathrm{~h}$ at $37^{\circ} \mathrm{C}$. Following incubation, $10 \mu 1$ MTT (Sigma-Aldrich; Merck KGaA, Darmstadt, Germany) was added to each well and incubated for a further $4 \mathrm{~h}$ at $37^{\circ} \mathrm{C}$. Cell proliferation was determined by measuring the optical density (OD) at a wavelength of $570 \mathrm{~nm}$ using a Fisherbrand $^{\mathrm{TM}}$ accuSkan $^{\mathrm{TM}}$ GO UV/Vis microplate spectrophotometer (Thermo Fisher Scientific., Inc.) and normalized to control cells (without transfection).

Western blot analysis. Total protein was extracted from cells using $\mathrm{xTractor}^{\mathrm{TM}}$ buffer (Clontech Laboratories, Inc.) and total protein was quantified using a bicinchoninic acid assay. Proteins were mixed with loading buffer and denatured at $95^{\circ} \mathrm{C}$ for $5 \mathrm{~min}$. In total, $40 \mu \mathrm{g}$ protein/lane was separated via SDS-PAGE on a $10 \%$ gel $(10 \%)$ and the separated proteins were transferred onto polyvinylidene difluoride membranes. Membranes were blocked for $1 \mathrm{~h}$ at room temperature with $5 \%$ skimmed milk. Subsequently, the membranes were incubated with rabbit anti human primary antibodies against Smad7 (1:2,000; cat. no. ab90086) and GAPDH (1:1,000; cat. no. ab9485; both Abcam, Cambridge, UK) overnight at $4^{\circ} \mathrm{C}$. Following primary incubation, the membranes were incubated with anti-rabbit IgG horseradish peroxidase-labeled secondary antibody (1:1,000; cat. no. MBS435036; MyBioSource, Inc., San Diego, CA, USA) for $2 \mathrm{~h}$ at room temperature. Protein bands were visualized using ECL ${ }^{\mathrm{TM}}$ Detection Reagent (cat. no. GERPN2105; Sigma-Aldrich; Merck KGaA). Smad7 protein expression was quantified using ImageJ software (version 1.47; National Institutes of Health, Bethesda, MD, USA) and normalized to the internal control, GAPDH.

Statistical analysis. Data were presented as the mean \pm standard deviation. All statistical analyses were performed using SPSS software (version 19.0; IBM Corp., Armonk, NY, USA). One-way analysis of variance followed by the least significant 


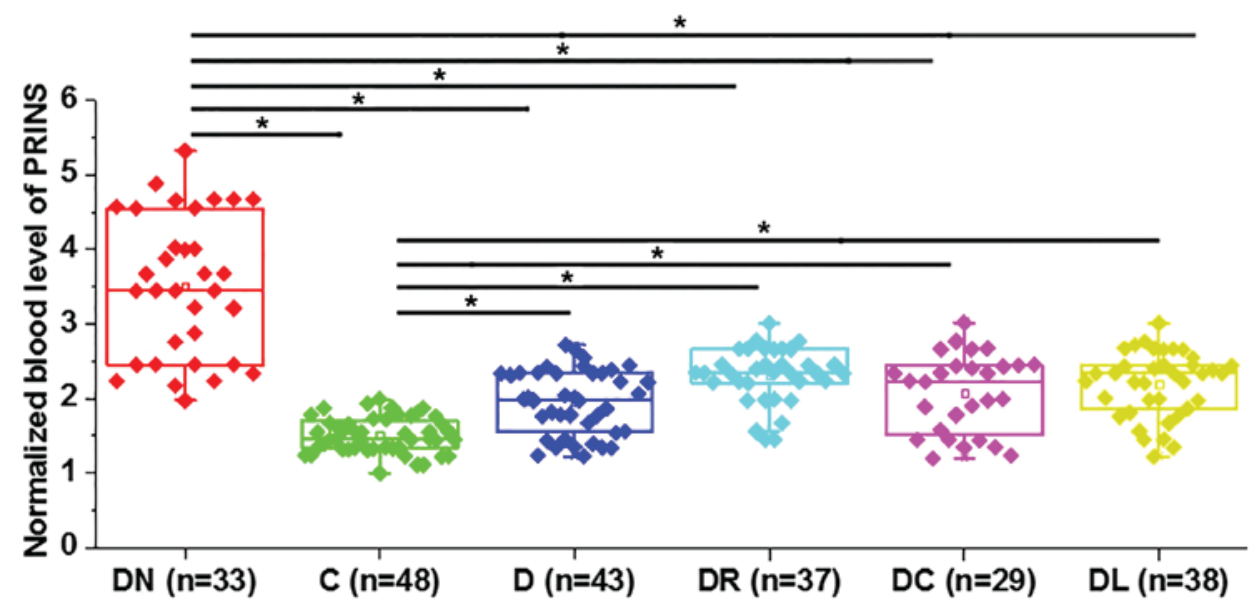

Figure 1. LncRNA PRINS expression in patients with diabetes. Serum PRINS expression levels were determined by RT-qPCR in patients with diabetes. "P<0.05. LncRNA PRINS, long non-coding RNA psoriasis-susceptibility-related RNA gene induced by stress; RT-qPCR, reverse transcription-quantitative polymerase chain reaction; DN, patients with diabetic nephropathy; $\mathrm{C}$, healthy controls; D, patients with diabetes without complications; DR, patients with diabetic retinopathy; DC, patients with diabetic cardiomyopathy; DL, patients with diabetic lung diseases.

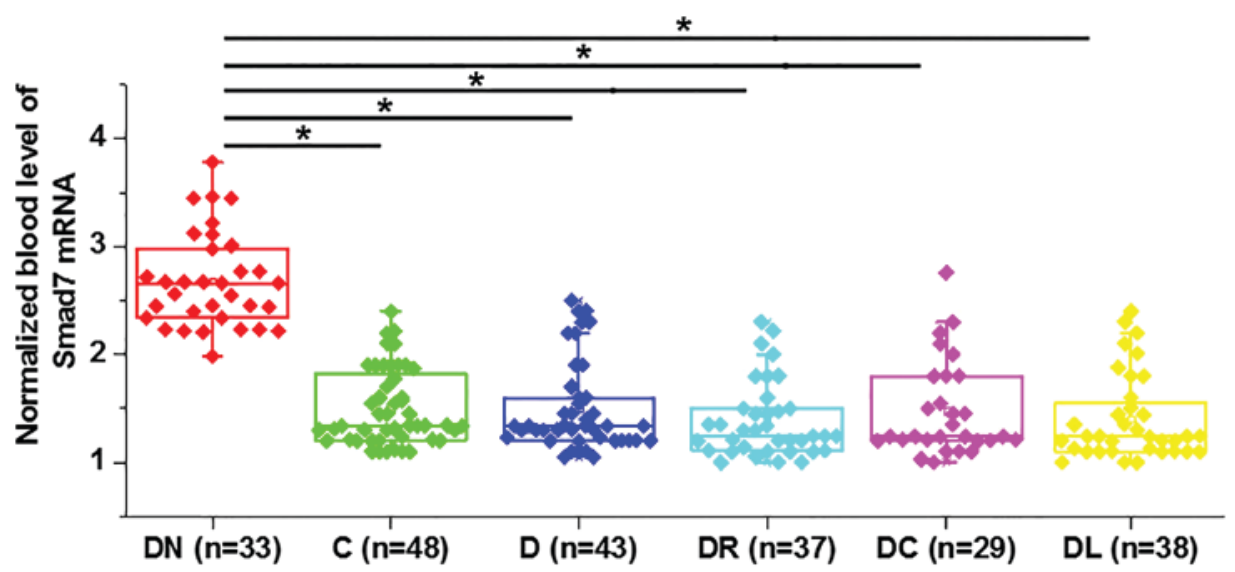

Figure 2. Smad7 expression in patients with diabetes. Serum Smad7 expression levels were determined by RT-qPCR in patients with diabetes. "P<0.05. Smad7, SMAD family member 7; RT-qPCR, reverse transcription-quantitative polymerase chain reaction; DN, patients with diabetic nephropathy; C, healthy controls; D, patients with diabetes without complications; DR, patients with diabetic retinopathy; DC, patients with diabetic cardiomyopathy; DL, patients with diabetic lung diseases.

difference test was used to analyze comparisons among multiple groups. Correlation analyses were performed using Pearson's correlation coefficient analysis. $\mathrm{P}<0.05$ was considered to indicate a statistically significant difference.

\section{Results}

Expression level of PRINS increases in patients with diabetes. Differential gene expression indicates whether a specific gene is involved in a particular biological process or disease. Initially the expression level of PRINS was detected by RT-qPCR in blood samples from patients with diabetes and healthy controls. The expression level of PRINS was significantly increased in all patient groups compared with healthy controls ( $\mathrm{P}<0.05$; Fig. 1). In addition, the expression level of PRINS was significantly increased in patients with diabetic nephropathy compared with other diabetes-related complications $(\mathrm{P}<0.05)$.

Expression level of Smad7 increases in patients with diabetic nephropathy. The expression level of Smad7 was detected by RT-qPCR in blood samples from patients with diabetes

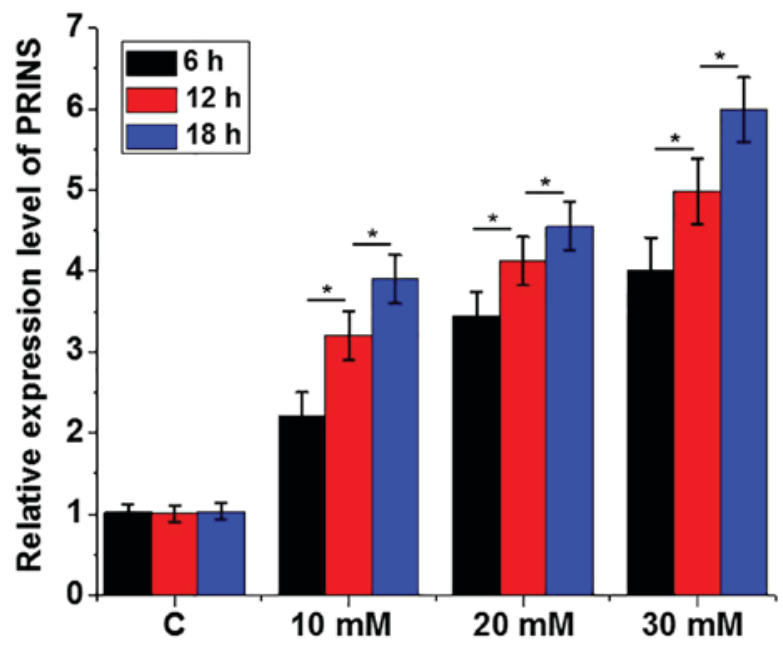

Figure 3. Treatment with high glucose upregulates the expression level of lncRNA PRINS in mouse podocyte cells. Concentrations of $5 \mathrm{mM}$ (control), 10,20 and $30 \mathrm{mM}$ D-glucose were used to treat mouse podocyte cells for 6,12 and $18 \mathrm{~h}$, respectively. Treatment with high glucose significantly upregulated the expression level of PRINS. * $\mathrm{P}<0.05$. LncRNA PRINS, long non-coding RNA psoriasis-susceptibility-related RNA gene induced by stress. 
A

Diabetic nephropathy
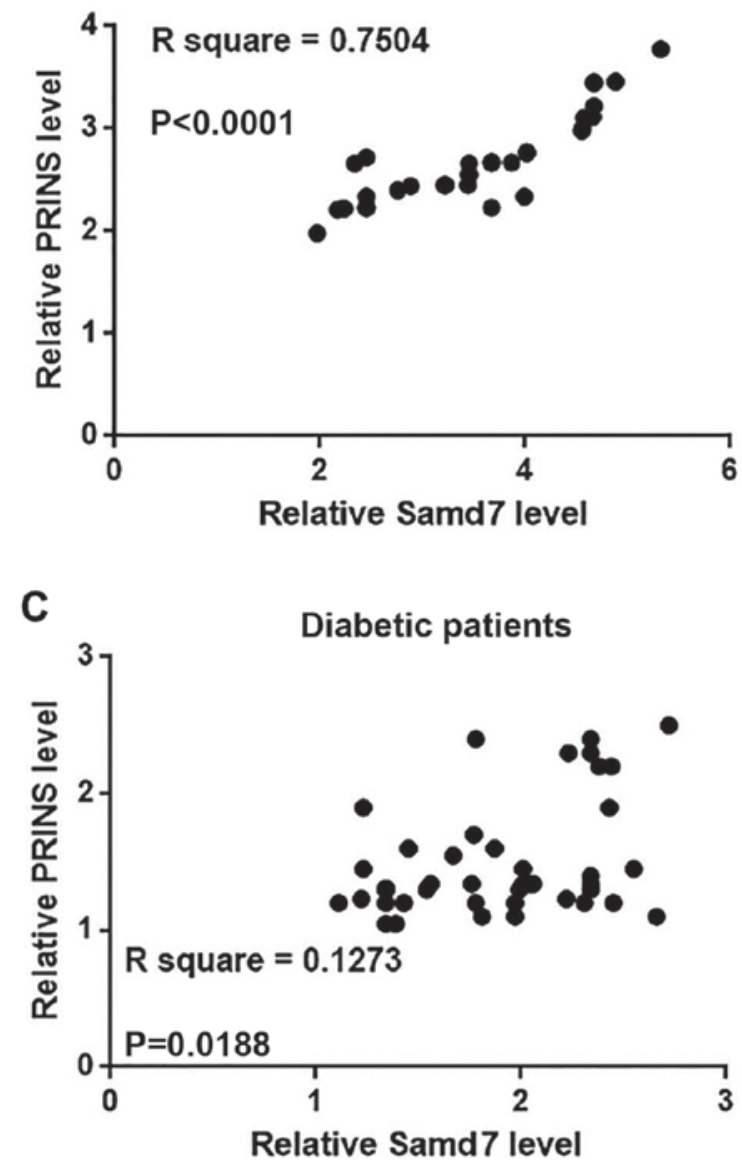

E

Diabetic cardiomyopathy

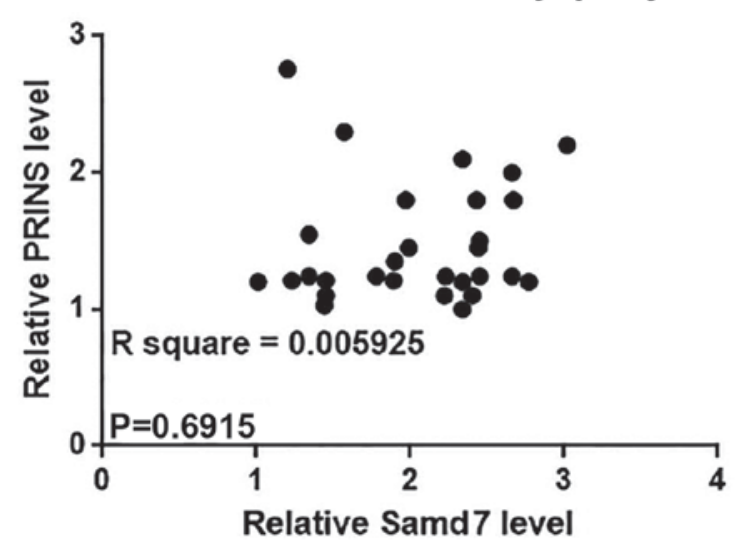

B

Healthy controls
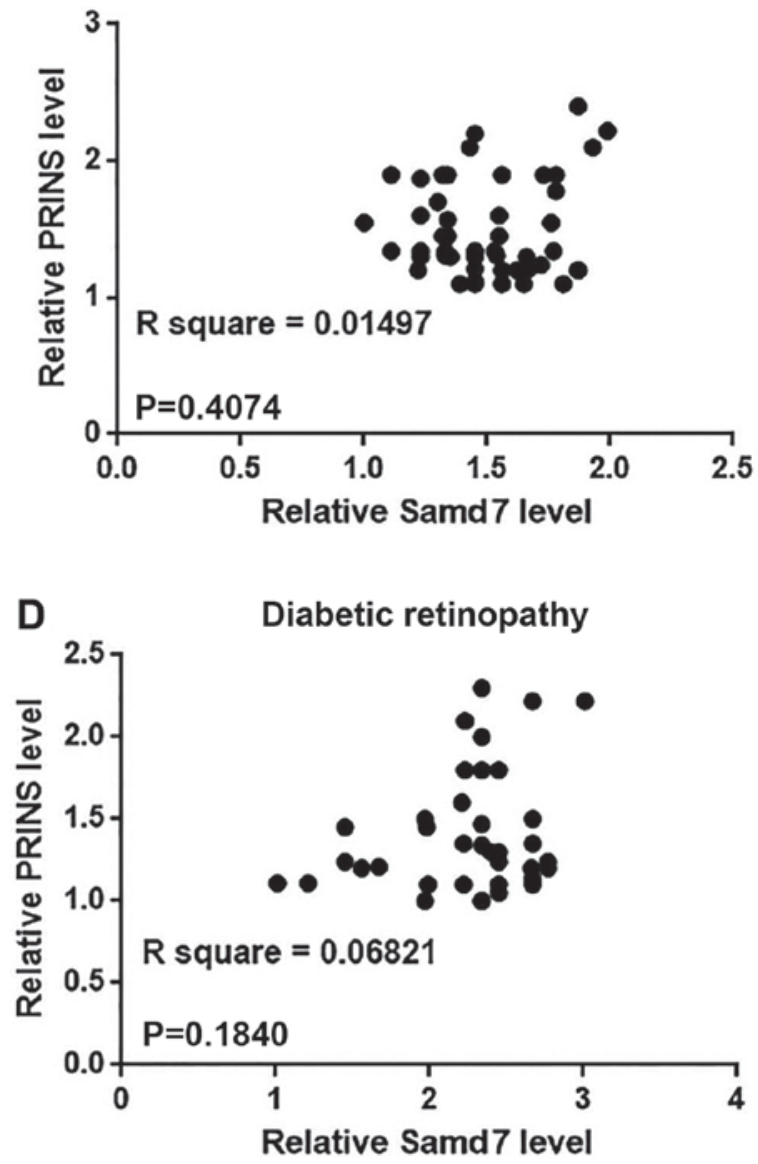

$\mathbf{F}$

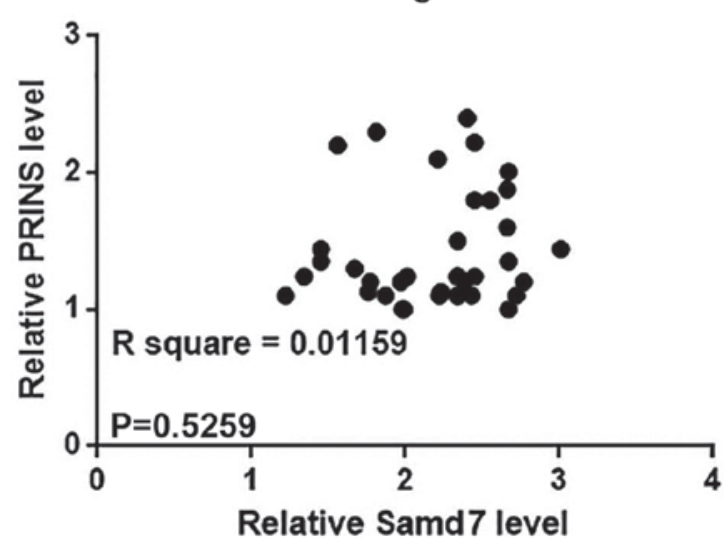

Figure 4. Correlation analysis between serum levels of 1ncRNA PRINS and Smad7 mRNA in patients with diabetes. Pearson's correlation coefficient analyses were performed to determine the association between the relative expression level of PRINS and Smad7 in blood samples from patients with (A) patients with diabetic nephropathy ( $\mathrm{r}=0.7504$; $\mathrm{P}<0.0001)$, $(\mathrm{B})$ healthy controls $(\mathrm{r}=0.01497 ; \mathrm{P}=0.4074),(\mathrm{C})$ diabetic patients without complications $(\mathrm{r}=0.1273$; $\mathrm{P}=0.0188)$, (D) patients with diabetic retinopathy $(\mathrm{r}=0.06821 ; \mathrm{P}=0.1840),(\mathrm{E})$ patients with diabetic cardiomyopathy $(\mathrm{r}=0.005925 ; \mathrm{P}=0.6915)$ and $(\mathrm{F})$ patients with diabetic lung diseases ( $r=0.01159 ; \mathrm{P}=0.5259)$. LncRNA PRINS, long non-coding RNA psoriasis-susceptibility-related RNA gene induced by stress; Smad7, SMAD family member 7 .

and healthy controls. The expression level of Smad7 was significantly increased in patients with diabetic nephropathy compared with other diabetes-related complications $(\mathrm{P}<0.05$; Fig. 2). However, no significant difference in the expression level of Smad7 was observed in patients with diabetes with other diabetes-related complications $(\mathrm{P}>0.05)$.
Treatment with high glucose upregulates the expression level of PRINS in mouse podocyte cells. Mouse podocyte cells derived from the renal glomerular basement membrane are essential for normal renal function and therefore these were used for all subsequent in vitro experiments. To further confirm the effects of high glucose on the expression of PRINS, mouse podocyte cells were 
A

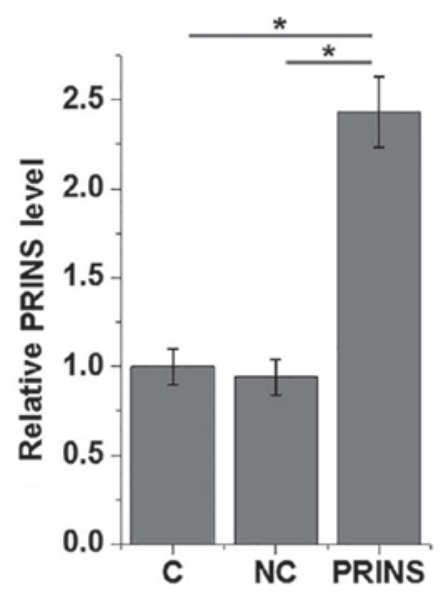

B

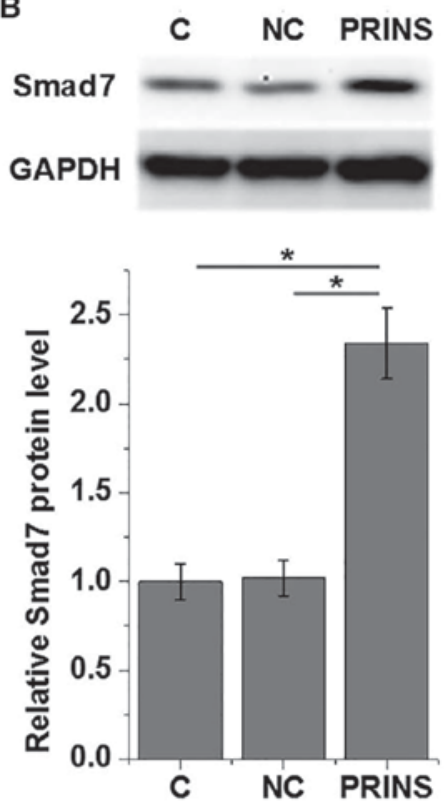

C

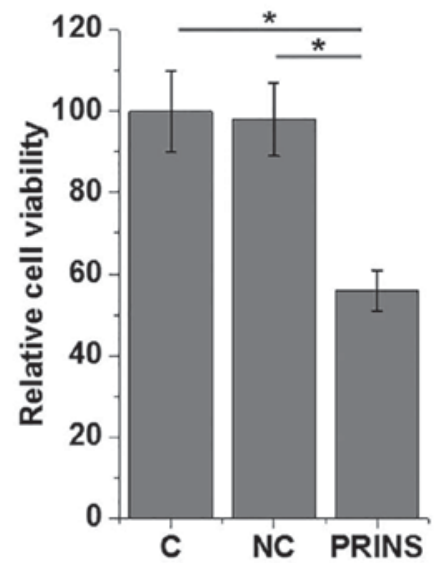

Figure 5. LncRNA PRINS overexpression upregulates Smad7 protein expression and reduces the viability of mouse podocyte cells under higher glucose treatment. (A) The relative expression level of PRINS was determined by RT-qPCR in mouse podocyte cells following transfection with PRINS expression construct. (B) The relative protein expression level of Smad7 was determined by western blot analysis and (C) cell viability was examined by MTT assay in mouse podocyte cells following transfection with PRINS expression construct. ${ }^{*} \mathrm{P}<0.05$. LncRNA PRINS, long non-coding RNA psoriasis-susceptibility-related RNA gene induced by stress; Smad7, SMAD family member 7; RT-qPCR, reverse transcription-quantitative polymerase chain reaction.

treated with $5 \mathrm{mM}$ (control), 10, 20 and $30 \mathrm{mM}$ D-glucose for 6,12 and $18 \mathrm{~h}$, respectively. Treatment with high glucose significantly upregulated the expression level of PRINS ( $\mathrm{P}<0.05$; Fig. 3).

Serum PRINS and Smad7 levels are significantly associated with diabetic nephropathy in patients with diabetes. Correlation analysis between the expression level of PRINS and Smad7 in blood samples from patients with diabetes was analyzed by Pearson's correlation coefficient analysis. A significant positive correlation between the relative mRNA expression level of PRINS and Smad7 was observed in patients with diabetic nephropathy $(\mathrm{P}<0.0001$; Fig. 4A). However, no correlation was observed between the expression level of PRINS and Smad7 mRNA in healthy controls (Fig. 4B), patients without complications (Fig. 4C), patients with diabetic retinopathy (Fig. 4D), diabetic cardiomyopathy (Fig. 4E) or diabetic lung diseases (Fig. 4F).

Overexpression of PRINS reduces cell viability and enhances Smad7 expression in mouse podocytes under higher glucose treatment. Overexpression of PRINS in mouse podocyte cells was confirmed by RT-qPCR following transfection with PRINS expression construct (Fig. 5A). Overexpression of PRINS significantly enhanced the expression of Smad7 protein in mouse podocyte cells $(\mathrm{P}<0.05$; Fig. $5 \mathrm{~B})$. In addition, Mouse podocyte cell viability under $30 \mathrm{mM}$ D-glucose was examined by MTT assay and the viability of mouse podocyte cells significantly decreased following overexpression of PRINS compared with control and negative control $(\mathrm{P}<0.05$; Fig. 5C).

\section{Discussion}

Previous findings demonstrated that PRINS is involved in kidney ischemia reperfusion injury (11) and allograft rejection in rat kidney transplantation (15), and therefore PRINS serves important roles in renal damage. In addition, the current study demonstrated that PRINS may be involved in the development of nephropathy in patients with diabetes, and PRINS may exert its biological function by upregulating Smad7 expression.

Treatment with high glucose can affect normal metabolism in patients with diabetes, which can directly or indirectly affect the expression of a large number of lncRNAs $(16,17)$. Expression patterns of IncRNAs can change depending on whether they accelerate or inhibit disease progression $(16,17)$. Circulating lncRNAs can serve as signaling molecules under pathological conditions to induce systemic reactions in patients with diabetes, including insulin resistance and accelerated senescence (18). Upregulation of PRINS was observed following acute tubule damage in rat kidney transplantation (15). The current study demonstrated that PRINS was significantly upregulated in patients with diabetes compared with healthy controls. In addition, PRINS expression was significantly upregulated in patients with diabetic nephropathy. Furthermore, treatment with high glucose significantly upregulated the expression level of PRINS in a time- and dose-dependent manner in mouse podocyte cells. Therefore, the upregulation of PRINS expression may be induced by both high glucose and renal damage. In addition, the level of serum PRINS may be used to distinguish patients with diabetes with diabetic nephropathy from those without renal damage.

A previous study reported that $\mathrm{Smad} 7$ overexpression is involved in the apoptosis of renal cells (6), and inhibition of renal apoptosis is considered to be a potential therapeutic target in diabetic nephropathy (7). However, Smad7 can also inhibit renal fibrosis in animal models of chronic kidney disease (19). Furthermore, Smad7 can serve a protective role in the mouse model of chronic aristolochic acid nephropathy (20). In the 
current study, the expression level of Smad7 was significantly upregulated in patients with diabetes compared with healthy controls, and in particular patients with diabetic nephropathy. Previous findings demonstrated that Smad7-deficient mice developed more severe diabetic kidney injury compared with wild-type mice under high glucose conditions, and although renal Smad7 had no effect on blood glucose, it significantly inhibited TGF- $/$ /Smad3-mediated renal fibrosis and the development of microalbuminuria in the rat diabetic model (21), indicating the protective role of Smad7 in diabetic nephropathy. The current study demonstrated that overexpression of PRINS decreased the viability of mouse podocyte cells, which are critical for renal function (22), and enhanced Smad7 protein expression. In addition, a significantly positive correlation between the expression of PRINS and Smad7 was observed in patients with diabetic nephropathy, however, no correlation was observed in patients with ther diabetes-related complications. PRINS may therefore serve different roles in diabetic nephropathy; it may promote the apoptosis of podocyte cells and upregulate Smad7 protein expression to inhibit GF- $\beta /$ Smad3-mediated renal fibrosis. However, further studies are required to understand more about this complex regulatory network.

In conclusion, the expression level of PRINS was significantly upregulated in patients with diabetes, and in particular patients with diabetic nephropathy. PRINS may be involved in diabetic nephropathy by enhancing Smad7 expression and renal apoptosis.

\section{Acknowledgements}

Not applicable.

\section{Funding}

No funding was received.

\section{Availability of data and materials}

The datasets used and/or analyzed during the current study are available from the corresponding author on reasonable request.

\section{Authors' contributions}

YQ designed the experiments. HJ performed the experiments. DX analyzed data. YQ drafted the manuscript. All authors read and approved the final manuscript.

\section{Ethics approval and consent to participate}

The current study was approved by the Ethics Committee at the Peace Hospital of Changzhi Medical College (Changzhi, China) and all participants provided written informed consent.

\section{Patient consent for publication}

The study followed the tenets of the Declaration of Helsinki and informed written consent was obtained from all participants.

\section{Competing interests}

The authors declare that they have no competing interests.

\section{References}

1. Guariguata L, Whiting DR, Hambleton I, Beagley J, Linnenkamp U and Shaw JE: Global estimates of diabetes prevalence for 2013 and projections for 2035. Diabetes Res Clin Pract 103: 137-149, 2014.

2. Ahlqvist E, Van Zuydam NR, Groop LC and McCarthy MI: The genetics of diabetic complications. Nat Rev Nephrol 11: 277-287, 2015.

3. Donate-Correa J, Martín-Núñez E, Muros-de-Fuentes M, Mora-Fernández C and Navarro-González JF: Inflammatory cytokines in diabetic nephropathy. Zhong Hua Tang Niao Bing Za Zhi 2015: 948417, 2015.

4. Lim AKH: Diabetic nephropathy-complications and treatment. Int J Nephrol Renovasc Dis 7: 361-381, 2014.

5. You H, Gao T, Cooper TK, Morris SM Jr and Awad AS: Arginase inhibition: A new treatment for preventing progression of established diabetic nephropathy. Am J Physiol Renal Physiol 309: F447-F455, 2015.

6. Yeung ML, Yao Y, Jia L, Chan JF, Chan KH, Cheung KF, Chen H, Poon VK, Tsang AK, To KK, et al: MERS coronavirus induces apoptosis in kidney and lung by upregulating Smad7 and FGF2. Nat Microbiol 1: 16004, 2016.

7. Isermann B, Vinnikov IA, Madhusudhan T, Herzog S, Kashif M, Blautzik J, Corat MA, Zeier M, Blessing E, Oh J, et al: Activated protein $\mathrm{C}$ protects against diabetic nephropathy by inhibiting endothelial and podocyte apoptosis. Nat Med 13: 1349-1358, 2007.

8. Nong Q, Li S, Wu Y and Liu D: LncRNA COL1A2-AS1 inhibits the scar fibroblasts proliferation via regulating $\mathrm{miR}-21 / \mathrm{Smad} 7$ pathway. Biochem Biophys Res Commun 495: 319-324, 2018.

9. $\mathrm{Xu} \mathrm{J}$ and $\mathrm{Xu}$ Y: The lncRNA MEG3 downregulation leads to osteoarthritis progression via miR-16/SMAD7 axis. Cell Biosci 7: 69, 2017.

10. Shi X, Sun M, Liu H, Yao Y and Song Y: Long non-coding RNAs: A new frontier in the study of human diseases. Cancer Lett 339: 159-166, 2013.

11. Yu TM, Palanisamy K, Sun KT, Day YJ, Shu KH, Wang IK, Shyu WC, Chen P, Chen YL and Li CY: RANTES mediates kidney ischemia reperfusion injury through a possible role of HIF-1 $\alpha$ and LncRNA PRINS. Sci Rep 6: 18424, 2016.

12. Szegedi K, Sonkoly E, Nagy N, Németh IB, Bata-Csörgo Z, Kemény L, Dobozy A and Széll M: The anti-apoptotic protein G1P3 is overexpressed in psoriasis and regulated by the non-coding RNA, PRINS. Exp Dermatol 19: 269-278, 2010.

13. Chinese Medical Association for Diabetes Mellitus, a Group of Microvascular Complications: China expert consensus for the prevention and treatment of diabetic nephropathy (2014 edition). Chin J Diabetes 6: 792-801, 2014 (In Chinese).

14. Livak KJ and Schmittgen TD: Analysis of relative gene expression data using real-time quantitative PCR and the 2(-Delta Delta C(T)) method. Methods 25: 402-408, 2001.

15. Zou XF, Song B, Duan JH, Hu ZD, Cui ZL and Yang T: PRINS Long Noncoding RNA involved in IP-10 mediated allograft rejection in rat kidney transplant. Transplant Proc 50: 1558-1565, 2018.

16. Zhao XY and Lin JD: Long noncoding RNAs: A new regulatory code in metabolic control. Trends Biochem Sci 40: 586-596, 2015.

17. Kornfeld JW and Brüning JC: Regulation of metabolism by long, non-coding RNAs. Front Genet 5: 57, 2014.

18. Carter G, Miladinovic B, Patel AA, Deland L, Mastorides S and Patel NA: Circulating long noncoding RNA GAS5 levels are correlated to prevalence of type 2 diabetes mellitus. BBA Clin 4: 102-107, 2015.

19. Lan HY: Smad7 as a therapeutic agent for chronic kidney diseases. Front Biosci 13: 4984-4992, 2008.

20. Dai XY, Zhou L, Huang XR, Fu P and Lan HY: Smad7 protects against chronic aristolochic acid nephropathy in mice. Oncotarget 6: 11930-11944, 2015.

21. Chen HY, Huang XR, Wang W, Li JH, Heuchel RL, Chung AC and Lan HY: The protective role of Smad7 in diabetic kidney disease: Mechanism and therapeutic potential. Diabetes 60: 590-601, 2011.

22. Rubio-Navarro A, Sanchez-Niño MD, Guerrero-Hue M, García-Caballero C, Gutiérrez E, Yuste C, Sevillano Á, Praga M, Egea J, Román E, et al: Podocytes are new cellular targets of haemoglobin-mediated renal damage. J Pathol 244: 296-310, 2018. 